\title{
Online Courses As a Form of Professional Development: Russian Local University Teachers' Experiences
}

\section{Svetlana Vladimirovna Mitrukhina}

Khakassia State University named after N.F. Katanov, the city of Abakan, Republic of Khakassia, Russian Federation

\section{Abstract}

Modern education is a phenomenon that combines offline education (traditional, classroom education) and online education (innovative, distance education), and in recent years its second form has become widespread that it is perceived as a direct threat to the existence of the first one. In a social, scientific and teachers' field an ambiguous attitude towards online education phenomenon has developed, educational researchers study both positive characteristics of distant education (massiveness, accessibility, various areas, an opportunity to study at any time in any place) and circumstances suggesting some vigilance towards this form of education

Corresponding Author: Svetlana Vladimirovna Mitrukhina

mitruhina_lana80@mail.ru

Published: 21 January 2021

Publishing services provided by Knowledge E

(c) Svetlana Vladimirovna Mitrukhina. This article is distributed under the terms of the Creative Commons

Attribution License, which permits unrestricted use and redistribution provided that the original author and source are credited.

Selection and Peer-review under the responsibility of the XXIII International Conference Conference Committee. (not suitable for developing practical skills, there is no precise contact, a low number of students finish courses). Online education is a popular form of modern distance education, implemented through massive open and massive closed educational courses, that is, online courses of specific universities which are placed on world and domestic educational platforms. If, regarding the training of young people (students) through online technologies, the debate about the appropriateness and effectiveness of this form does not subside, then for teachers and university leadership (especially a provincial), online courses are almost a panacea for solving the problem of advanced training. In this research online courses are studied as a form of a university teacher's professional development. Informal interviews with professors' Khakas State University named after N.F. Katanov, who had an online course experience, were conducted. The study has revealed the reasons teachers' satisfaction of this form of this education form and some aspects of their positive and negative experience, etc.

Keywords: distant education, online learning, online courses, massive open online courses, mass closed online courses.

\section{Introduction}

According to human capital theory education is studied as an investment, which will make a good profit in future from financial and social points of view.

Requirements of technology society change a modern system of education, forcing a modern person to invest plenty of resources into human capital. It is deemed, that 
develop his / her qualification systematically and unplanned, refresh and make his / her skills more profound.

New notions have appeared in education, such as micro-learning, micro Masters, nanodegree, snack learning, online learning and so on. For modern people the Internet has become an entertainment, a professional field and means of receiving education.

In popular scientific literature you might come across statements, which seem to appear more often, that in future, short-term education certificates, such as online courses will be in high demand rather than diplomas (Bachelor's degree, Master's degree, Specialist Degree)

In fact, latterly, the popularity of distant education and online courses has increased among young students and adults, which can be shown by a number of educational platforms, a number of online courses on them and a number of registered listeners.

A university staff needs to refresh knowledge and get new information, as he / she has to keep up with the modern world and be aware of new trends in teaching etc. Therefore, online education is becoming highly demanded in teaching area, in the age of an endless urge to new information, on the one hand, and, on the other hand, lack of free time, financial resources, thus, it can be considered as the most accessible means of professional development.

If a professor is geographically separated from educational centers, then online learning is practically the only way to develop professionally, not been torn away from professional responsibilities.

In complex economic conditions the local university administration has to recommend this form of education to its staff, as it is convenient and accessible: due to his / her professional engagement, every professor is equipped with necessary computer technology and has access to the Internet, a teacher does not have to be torn away from his family and chores, what is more, an experienced teacher does not need as much face-to-face interaction with an author of the course as a young student. In addition, online education allows a university to save ample finances: at once a large number of professors does not have to pay a subsistence allowance etc.

Therefore, a demand appeared to study online education as means of a university teacher's professional development through high quality data analysis, which was obtained by an informal interview with teachers, who had an online course experience. 


\section{Methodology and Methods}

Methodological and theoretical basis for research are statements of Russian and foreign sociologists, studying overall problems of high education and distant high education in particular.

Online education as an investment in future social wealfare is studied in the realm of human capital theory (Schultz T, Becker G, Bourdieu P, Dolan A, Lindsey G, Haney P, Draganchuk L.S, Dyatlov S.A. and others)

Empirical basis of the research included regulations of high education in the Russian Federation analysis, Russian and international Internet resources, in addition, the results of high quality analysis of informal interviews with university staff of Khakas State University named after Katanov N. F.

\section{Results and Discussion}

Thanks to a wide spread of the Internet in education, offline (traditional, classroom based) and online (innovative, distant) education are distinguished.

In pedagogical literature, online education is studied as distant educational technology. Distant education is a mean of receiving education, where information exchange and feedback between teachers and students is implemented from a distance via computer networks.

Online learning (e-learning) is a way to obtain knowledge and skills at a distance in online environment (here and now) with the help of a computer or other gadgets connected to the Internet. In this case, online learning is means of obtaining knowledge and interaction between a teacher and a student with the help of the Internet connection and gadgets.

In both cases, there is some distance between a teacher and a student and there is no face-to-face interaction.

Online course is means of electronic learning, which means organised and goaloriented educational process, realized on the basis of technical means of modern information technologies (as well as information and communication technologies) and logical and structurally accomplished educational unit, methodologically equipped with unique totality of classified electronic means of education and control [2]. 
It is necessary to distinguish between two kinds of online courses: massive open online courses (e.g. Coursera) and mass closed online course or a university online course.

Nowadays the most widely spread and highly demanded form of realization of online education are massive online courses. Massive online courses were well developed in 2012, when major world educational platforms such as Coursera, Udacity, FutureLearn, OpenClassrooms, OpenLearning, edX and others started working almost simultaneously. Many online courses on these educational platforms were created under supervision of teachers of leading universities: Coursera - teachers of Stanford University, EdX- Massachusetts Institute of Technology [5].

These world educational platforms are really popular, on platform Coursera more than 10 million people as listeners are registered [4].

As for Russian educational platforms, they also became widely spread, for instance, the project National platform of open education includes 469 online courses.

Massive open educational courses, judging from its titles, are characterized by massiveness, openness, free of charge basis, possibility not to finish education.

In the context of the topic of our research it is more correct to use a notion "Mass closed online courses" - a complex system of distant learning, university online courses, aimed at finishing online learning and getting a proper qualification for listeners.

Often in pedagogical literature, online learning is studied as an innovative educational technology. This poses a question: what reveals its innovation? If its context is discussed, then on the inside an online course includes fairly traditional components (theoretical part, test control, video plots for revision and so on), that is everything that characterizes an offline learning as well. Its novelty is shown in accessibility of this form of education for large social groups as well as for a particular person.

The university staff plays a special role in online training, he / she does not work on his / her own, a whole team often works on creating the course, starting from technical workers and ending with tutors, instructors who support and supervise students.

We consider the essence of online training through the prism of its positive and negative sides.

Let us dwell on the positive characteristics of the phenomenon of online learning, such as:

1. convenience for those who for some reason (disability, the presence of young children, work, geographic distance from the place of residence, etc.) cannot study offline; 
2. free or low cost training compared to offline training;

3. students' independence of the course from a far distant place and time;

4. universality: online courses can be either highly specialized or targeted at the general public;

5. the perso's opportunity to undergo training at the sites of leading universities, listen to the course of an authoritative teacher and gain knowledge not only in his specialty, but also in related industries;

6. flexibility, training at an individual pace, the listener himself can distribute the time necessary for the assimilation of information, he can once again return to the material passed;

7. designing one's own educational space: the content of offline education is quite strictly defined by the requirements of various regulatory documents (in a Russian university, by the requirements of federal state educational standards) and it's difficult to make changes to the list of curriculum disciplines;

8. equal conditions accessibility for representatives of different social groups;

9. the person's ability to analyze or compare interesting and uninteresting courses, «strong» and «weak» teachers and make a choice.

Despite the advantages mentioned above, online training opportunities are limited by the following circumstances:

1. this form of training is optimal for obtaining or updating knowledge is not suitable for practicing practical skills and, as a result, there are areas in which it is necessary to use online training with caution (for example, medicine)

2. in online training there is a lack of precise direct verbal and non-verbal contact;

3. in online courses, as a rule, a simple system of knowledge control (tests) is used and it is not clear what is specifically controlled (often points are given simply for students' activity);

4. the objectivity of the assessment of training results is also in doubt, because the student, solving tests, can easily resort to the help of other Internet resources, of other people;

5. training result is not important, the main thing is that there is an interest and motivation of the listener; 
6. when taking online courses, technical problems may appear (problems with the Internet, with a specific site);

7. due to the lack of a coercion mechanism, a large dropout is observed among students; not all registered on an online course complete their studies.

The advantages and disadvantages of online training, highlighted above, do not overlap and do not tip the scales towards online or offline training. Among experts in the field of education, there is an increasing opinion that a combination of both forms is skillful, that online training should deepen and continue offline training but not replace it [3].

Since there is already a widespread practice of online training, including a provincial university as well, there is a need for its understanding and analysis.

Since 2018 the students and university staff at the Katanov Khakass State University have been actively studying online courses, most often on the national educational platforms «Open Education» and educational courses posted on the website of the Regional Competence Center for Online Learning «e-Siberia» in Krasnoyarsk.

Let us dwell on the teaching experience in detail. Online courses for university staff are not only a means of building capacity and complementing formal education, it is the most rational way to solve the problem of improving skills and not to do significant harm to the university economy.

To identify the personal unique attitude of the university staff to online learning as a form of advanced training, a qualitative research method was chosen in the form of an informal interview.

Most of the interviews were devoted to nostalgic memories of past years, when the university sent its staff on two-week business trips to the leading educational centers of Siberia (Krasnoyarsk, Novosibirsk, Tomsk), of those collective trips for corporate spirit and establishing interesting and useful social contacts with colleagues from other places.

These interviews has shown that the general attitude of teachers at KKhSU to online learning as a form of study at the university is rather negative; almost everyone perceives it as a threat to their work. Such resistance on the part of the staff is caused by fear that they will be «replaced by a computer», «hours and bids will be reduced», that there will be no need in their work ", and «they will be completely dismissed».

Most of the respondents are dissatisfied with the subject of the courses offered for them as refresher courses. 
Among the reasons that prompted the staff to take online courses, outwardly motivated answers are: it was not their free choice and their own interest, but the requirement (on the part of management and regulatory documents for staffing educational programs) to improve systematically their skills and have a document (certificate) about passing educational courses. At that time the search for an educational platform, the university, the name of a specific online course was chosen not by the teacher himself / herself, but by the university administration. The topics of such pre-selected online courses were not specialized and did not meet the teaching interests, for example, respondents enumerated such courses as «First Aid», «Preparing an effective presentation», etc. Hence, satisfaction with the results of such courses is low and the assessment of the possibility of using the acquired knowledge in their professional activities is low.

However, among the respondents there were those who chose the online course based on their own interest or the specifics of the taught disciplines. Such respondents were pleased with the results of online refresher courses.

As for the question of positive aspects they mark online learning as a form of advanced training for university staff, pragmatic answers were received: «the ability to download material and then use material in activity», «having passed such a course, I have gained the necessary experience, I would use it in my practice», etc. The negative sides noted by the respondents are more related to the technical side of the issue or problems with the self-discipline of the respondents:

1. the majority of respondents (most over 55) experienced difficulties working on a computer, starting from registering for a course and ending with solving the final assignment. Help was provided by younger colleagues, therefore, together they managed to overcome difficulties;

2. since the professors were busy with their main activities, it was difficult to take online courses in the evening or even at night and learn several topics and sections at once which had a bad effect on the assimilation of information. The majority of respondents hardly remembered the content of the training, «the information did not stay for a long time»;

3. there were claims that it was difficult to comply with the deadline singled out for the mastering of a specific block of information or the entire course.

Among the respondents there were also those who spoke about the sociopsychological specifics of online learning: the lack of lively communication and social connections, contacts between groupmates. 


\section{Conclusions}

The phenomenon of «online learning» is ambiguously perceived by the public consciousness; there are significant advantages that allow us to talk about the mass demand for this form of training, as well as significant disadvantages that impose restrictions on the widespread use in the educational activities of the university.

Provincial university staff training in online courses is the most rational form of advanced training in modern conditions, which allows them solving the problem in a short time and at a low cost. However, it is necessary to improve the efficiency, effectiveness of online training and university staff satisfaction, to optimize both the technical and the substantive sides of the issue.

\section{Acknowledgments}

The reported study was funded by RFBR according to the research project № 19-01100365 .

\section{References}

[1] Chekhonina, O. B. and Kuznetsova, S. A. (2018, November). Mass Open Online Courses as a Means of Continuing Education of a University Teacher. In: Proceedings of the Experience and Prospects of Online Learning in Russia, Russia, Sevastopol: Branch of Moscow State University in Sevastopol, pp. 79-82.

[2] Grechushkina, N. V. (2018). Online Course: Definition and Classification. Higher education in Russia, vol. 6, issue 27, pp. 125-134.

[3] Kuzminov, Y. I. and Frumin I. D. (2015). Online Learning: How it Changes the Structure of Education and the University's Economy. Open discussion Ya. I. Kuzminov - M. Karnoy. Education Issues, vol. 3, pp. 8-43.

[4] Makoveichuk, K. A. (2015). Prospects for the Use of Courses in the MOOC Format in Higher Education in Russia. International Research Journal, vol. 6, pp. 66-67.

[5] Mozhaeva, G. V. (2015). Mass Online Courses: A New Vector in the Development of Continuing Education. Open and Distance Education, vol. 2, issue 58, pp. 56-65.

[6] Rotar, O. (2018, March). Adult Learners in Online Higher Education: The Complexity of Students' Transitional Experience of Becoming a Distance Learner. In A. Tawell, et al (Eds.), Technology Matters: Proceedings of the 2018 STORIES Conference. Oxford: STORIES Conference, pp. 30-43. 